\title{
Sudden Infant Death Syndrome In Twins
}

- Is There A Risk To The Survivor?

Richard Lee-Kelland, Fiona Finlay

Department of Community Paediatrics, Virgincare, St Martin's Hospital, Bath.

\section{INTRODUCTION}

- At a child death overview panel meeting, sudden infant death syndrome (SIDS) was recorded as the cause of death in two separate cases where the infant was one of twins.

- A panel member asked: what was the likelihood of a second twin dying in these cases, and would it would be advisable to admit the surviving twin to hospital?

- The current guidance from the Royal College of Pathologists is that these twins should be admitted for observation. This is based on a single study (Malloy 1999) which found an eightfold increase in relative risk (RR) of death in the surviving twin from SIDS compared to a singleton pregnancy. - We wondered if there was any further research

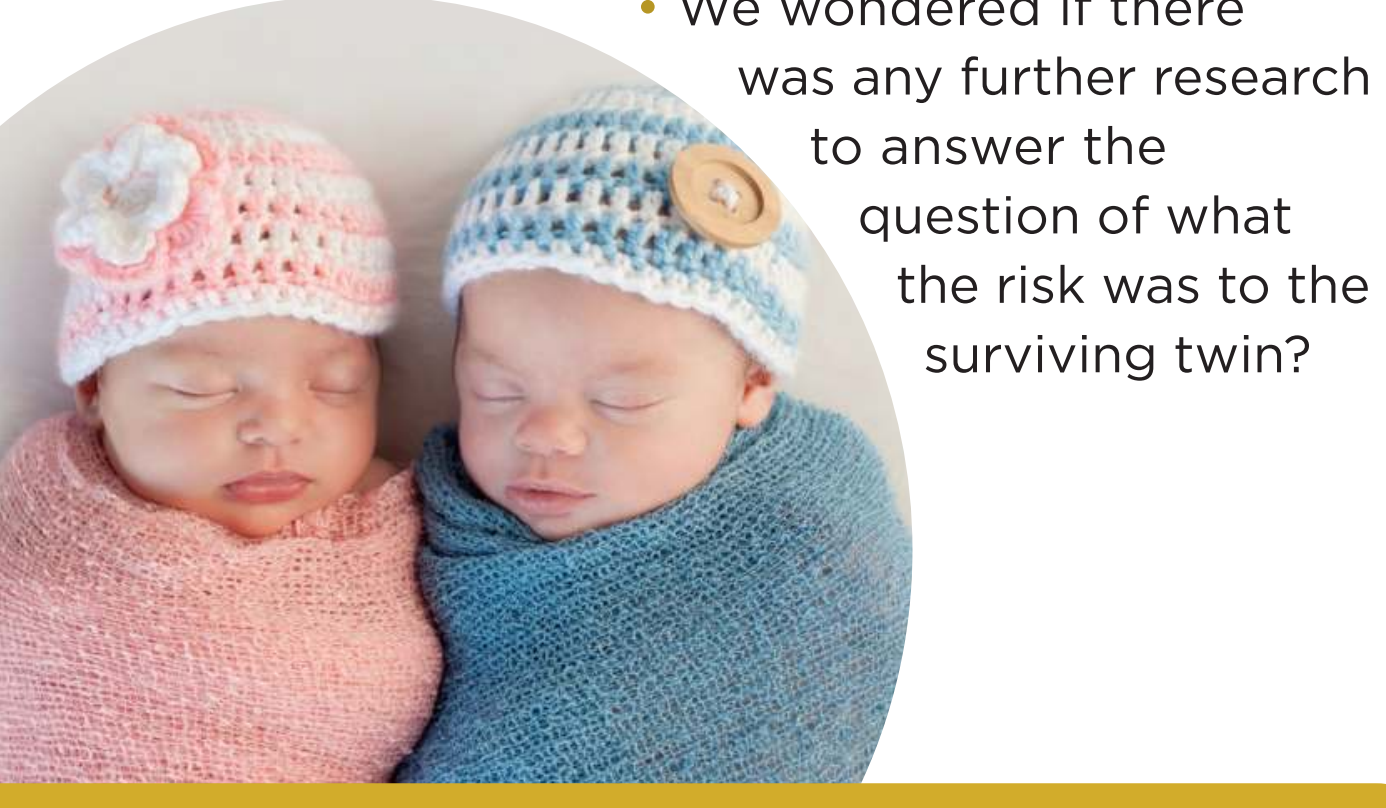

\section{OBJECTIVES}

\section{To complete a systematic review of the} literature to assess:

1. The overall risk of death in from SIDS in the surviving twin

2. What is the immediate risk of SIDS in the surviving twin

\section{METHOD}

A systematic literature review and analysis was completed using the Medline, EMBASE and Cochrane databases to assess the question.

The following search strategy was used: (SIDS[Title/Abstract]) OR

"sudden infant death"[Title/Abstract])

$O R$ "cot death"[Title/Abstract]) OR

"crib death"[Title/Abstract]) OR

"sudden infant death"[MeSH Major Topic])

AND ((twin[Title/Abstract]) OR

sibling[Title/Abstract]) OR

"twin studies as topic"[MeSH Major Topic])

\section{RESULTS}

\section{A total of 116 studies were identified through the search strategy, these were reviewed and two adequately addressed the study objectives:}

\begin{tabular}{|l|l|l|l|}
\hline \multicolumn{1}{|c|}{} & Study Type & Location & Participants \\
\hline Malloy (1999) & $\begin{array}{l}\text { Retrospective } \\
\text { cohort study }\end{array}$ & USA & $\begin{array}{l}\text { US-linked birth and infant death certificate } \\
\text { tapes for the years 1987 through 1991 }\end{array}$ \\
\hline Gertahun (2004) & $\begin{array}{l}\text { Retrospective } \\
\text { cohort study }\end{array}$ & USA & $\begin{array}{l}\text { National Center for Health Statistics Linked } \\
\text { Birth and Infant Death files (1995-1998) }\end{array}$ \\
\hline
\end{tabular}

\section{Is there an increased risk of death in the survivor?}

A Meta-anaylsis of the two studies was completed. The results are shown in the forest plot below. Overall there was an statically significant increased risk of SIDS in the surviving twin compared to the overall risk of SIDS in twins.

\begin{tabular}{|c|c|c|c|c|c|c|}
\hline \multirow[b]{2}{*}{ Study or Subgroup } & \multicolumn{2}{|c|}{$\begin{array}{l}\text { SIDS in } \\
\text { surviving twin }\end{array}$} & \multicolumn{2}{|c|}{$\begin{array}{l}\text { SIDS in } \\
\text { twins overall }\end{array}$} & \multirow[b]{2}{*}{ Weight } & \multirow{2}{*}{$\begin{array}{c}\text { Risk Ratio } \\
\text { M-H, Fixed, 95\% Cl }\end{array}$} \\
\hline & Events & Total & Events & Total & & \\
\hline Getahun 2004 & 3 & 498 & 501 & 392878 & $25.0 \%$ & $4.72[1.52,14.65]$ \\
\hline Malloy 1999 & 7 & 767 & 1056 & 425941 & $75.0 \%$ & $3.68[1.76,7.71]$ \\
\hline Total (95\% Cl) & & 1265 & & 818819 & $100.0 \%$ & $3.94[2.12,7.32]$ \\
\hline Total events & 10 & & 1557 & & & \\
\hline \multicolumn{4}{|c|}{$\begin{array}{l}\text { Heterogeneity: } \mathrm{CHi}^{2}=0.13, \mathrm{df}=1(\mathrm{P}=0.72) ; \mathrm{I}^{2}=0 \% \\
\text { Test for overall effect: } \mathrm{Z}=4.34(\mathrm{P}<0.0001)\end{array}$} & \multicolumn{3}{|c|}{ Risk Ratio } \\
\hline & & \multicolumn{2}{|c|}{ Study or Subgroup } & \multicolumn{3}{|c|}{ M-H, Fixed, 95\% Cl } \\
\hline & & \multicolumn{2}{|c|}{ Getahun 2004} & & & $\longrightarrow$ \\
\hline & & \multicolumn{2}{|c|}{ Malloy 1999} & & & 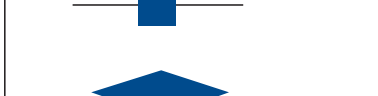 \\
\hline & & \multicolumn{2}{|c|}{ Total (95\% CI) } & & & \\
\hline & & \multicolumn{2}{|c|}{ Total events } & 0.05 & 0.2 & 20 \\
\hline
\end{tabular}

\section{What is the immediate risk of SIDS in the surviving twin?}

One study (Malloy 1999) recorded the risk of death from SIDS on the same day in the surviving twin. In only one of these seven did both twins die on the same day (rate ratio, 0.58 per 100,000 twin pregnancies).

\section{CONCLUSION}

- Although rare, there is an increased risk of death in the surviving twin when compared to the overall risk of SIDS for a twin.

- Studies are not current and not completed in the UK.

- Following presumed SIDS, it remains prudent to admit the surviving twin for observation and investigations to exclude sepsis, cardiac abnormality or inherited metabolic disease.

- However, the risk of death within the same day from SIDS is very low. 